\title{
Pathogenesis regarding development and structure of unstable atherosclerotic plaque in internal carotid artery in relation to high risk factors of an ischaemic stroke. Current status of knowledge
}

\author{
Natalia Wiśniewska, Emil Kania, Adam Płoński, Jerzy Głowiński \\ Department of Vascular Surgery and Transplantation, the Medical University of Bialystok Clinical Hospital, Poland
}

\begin{abstract}
Worldwide, stroke is the second leading cause of death and a major cause of disability. However, the mortality of stroke differs between countries and geographical regions. In high-income countries, i.e. in the United States, stroke has fallen from the third to the fourth leading cause of death. The risk for ischaemic stroke increases with the degree of internal carotid artery stenosis. 70-99\% carotid artery stenosis (according to NASCET) in symptomatic patients is an indication for a vascular intervention since this group will achieve significant benefits from surgical treatment. Asymptomatic patients with 60-99\% (according to NASCET) carotid artery stenosis may also benefit from surgical procedures when at least one-factor conditioning a high risk of ischaemic stroke incidence exists. These factors may include morphological structure features of atherosclerotic plaque described in imaging examinations that are indicative of its instability and specific clinical predispositions. The paper presents stages of unstable atherosclerotic plaque development and features of its morphological structure that may significantly increase the risk for ischaemic stroke and compares them with current guidelines: Management of Atherosclerotic Carotid and Vertebral Artery Disease: 2017 Clinical Practice Guidelines of the European Society for Vascular Surgery (ESVS).
\end{abstract}

Key words: endothelium, carotid artery, atherosclerotic plaque, plaque instability, stroke

Acta Angiol 2019; 25, 3: 145-156

\section{Introduction}

At present, atherosclerosis constitutes one of the main causes of morbidity and mortality in the modern population. Since the disease manifests itself clinically only in the middle and elderly age, its social and economic significance will probably continue to increase due to aging of societies. However, studies show that early atherosclerotic lesions may be detected in humans already in their childhood, or even their foetal life [1]. Although atherosclerosis is called a civilization disease of the $2 \mathrm{I}^{\mathrm{st}}$ century, according to the research of American scientists it existed in ancient societies. Bodies of mummies that had undergone CT scans revealed advanced wall calcifications of large and medium arteries, including carotid arteries. The severity of lesions correlated positively with an estimated age of the examined individuals at the time of death. These discoveries confirmed the fact that modern lifestyle is not the only reason for cardiovascular diseases and that their incidence may be a consequence of a natural process- aging of a human body. It is only the severity of atherosclerotic lesions that resembles the influence of other contemporary factors [2].

Address for correspondence: Natalia Wiśniewska, Department of Vascular Surgery and Transplantation, the Medical University of Bialystok Clinical Hospital, Marii Skłodowskiej-Curie 24a, 15-276 Białystok, Poland, e-mail: wisniewnatalia@gmail.com 
Atherosclerosis of large arteries, including carotid arteries, exerts a profound influence on public health. Stroke-associated mortality amounts to $10-30 \%$ and the patients who survived an ischaemic stroke are subject to subsequent ones [3]. According to a NASCET's study (The North American Symptomatic Carotid Endarterectomy Trial), in symptomatic patients, the risk for ipsilateral recurrent ischemic stroke amounts to $13 \%$ for stenosis above $70 \%$, and $4.4 \%$ for stenosis at the level of 50-69\% per year [3]. Among asymptomatic patients with stenosis at the level of $60 \%$ and higher, the risk for ischaemic stroke reaches $\mathrm{I}-2 \%$ per year [3]. However, the risk may be much higher in case of patients with the high-risk asymptomatic carotid artery stenosis (ACS) i.e. patients with specific characteristics regarding morphological structure of atherosclerotic plaque, and some clinical predispositions [4].

Over the years, indications for carotid artery stenosis surgical treatment have changed significantly [4]. The main criterion considered is the degree of an internal carotid artery stenosis. The severity of atherosclerotic lesions may be determined by applying numerous invasive and non-invasive diagnostic methods, which evaluate the degree of stenosis in percentage (\%). However, presently it is suggested that the best way of estimating the risk for ischaemic episodes is the evaluation of internal carotid artery stenosis expressed as a percentage (\%) accompanied by a patient's history with regard to past ischaemic strokes (documented ischaemic stroke or transient ischaemic attack) within the last 6 months, and evaluation of plaque morphology in terms of its instability. These changes are reflected in the current guidelines of the European Society for Vascular Surgery [5].

\section{Risk factors for atherosclerosis}

Atherosclerosis is defined as a chronic inflammatory response to a trigger factor damaging the arterial endothelium with phases of period activity, differentiated into the stages of development, severity, and extent. Atherosclerotic lesions develop mainly where the disturbed flow (shear stress) creates an atheroprone environment, especially in large arteries (aorta and branches), where blood pressure is high and the blood flow is not laminar - especially at the sites where arteries branch off [6]. Given the above mechanisms, the bifurcation of the common carotid artery is one of the sites that are mostly predisposed to develop atherosclerotic lesions.

Strongly documented modifiable factors that may potentially damage vascular endothelium include hyperglycemia, high blood homocysteine level, abnormal lipid profile, hypertension and smoking. Documented factors that cannot be controlled include age, male sex, and genetic factors that are frequently highlighted by many authors. Moreover, the following factors are suggested to be taken into consideration: deficit of certain vitamins and microelements in diet, low physical activity, excess weight and obesity, changes in hormone panel occurring in people due to aging, exposure to chronic and severe stress, and also some infective factors [7].

Genetic factors include not only genetically-determined familial hypercholesterolaemia, but also coagulation disorders, and indirectly genetic disorders of renin-angiotensin-aldosterone system (RAAS) leading to arterial hypertension, which is a significant risk factor for atherosclerosis as it creates conditions of turbulent blood flow [8]. Genetically-determined immunological disorders leading to exacerbation of inflammation within the arterial wall are also important factors. DEGs (differentially expressed genes) are genes that undergo a significantly different expression. Analysing differences in DEGs expression allows distinguishing between an advanced atherosclerotic lesion and an early one [9]. These genes expression changes along with the plaque developmental stage [9]. In most cases DEGs are related to immune response and maintain chronic inflammatory process, wich indicates a signifcant role of the immune response in the pathogenesis of atherosclerosis [9]. The analysis of DEGs profile in atherosclerotic carotid plaque revealed that upregulated genes were associated with inflammatory response and chemotaxis signal pathways within the immune system [10]. Downregulated genes were associated with contraction and cellular cytoskeleton structure of the vascular smooth muscle cells [10]. Furthermore, the analysis of DEGs showed that genes associated with antigen presentation are of key importance in development of atherosclerotic lesions [9]. Some DEGs may be a potential therapeutic targets [9].

\section{The beginning}

Endothelium that lines arterial walls is a structure whose function influences the balance between coagulation and fibrinolysis, functions of the immune system, regulation of arterial blood pressure, and angiogenesis [II, I2]. Endothelial cells are highly differentiated and specializedwhile having a limited ability to regenerate. An important function of the arterial endothelium is to secrete factors responsible for vasoconstriction and dilatation to maintain proper arterial wall tone, which is mostly dependent on the normal secretion of nitric oxide (NO) acting as a counterbalance for angiotensin II and endothelin I [12]. During the initial stage of atherosclerotic plaque formation, disadvantageous conditions of blood flow influence the endothelium. 


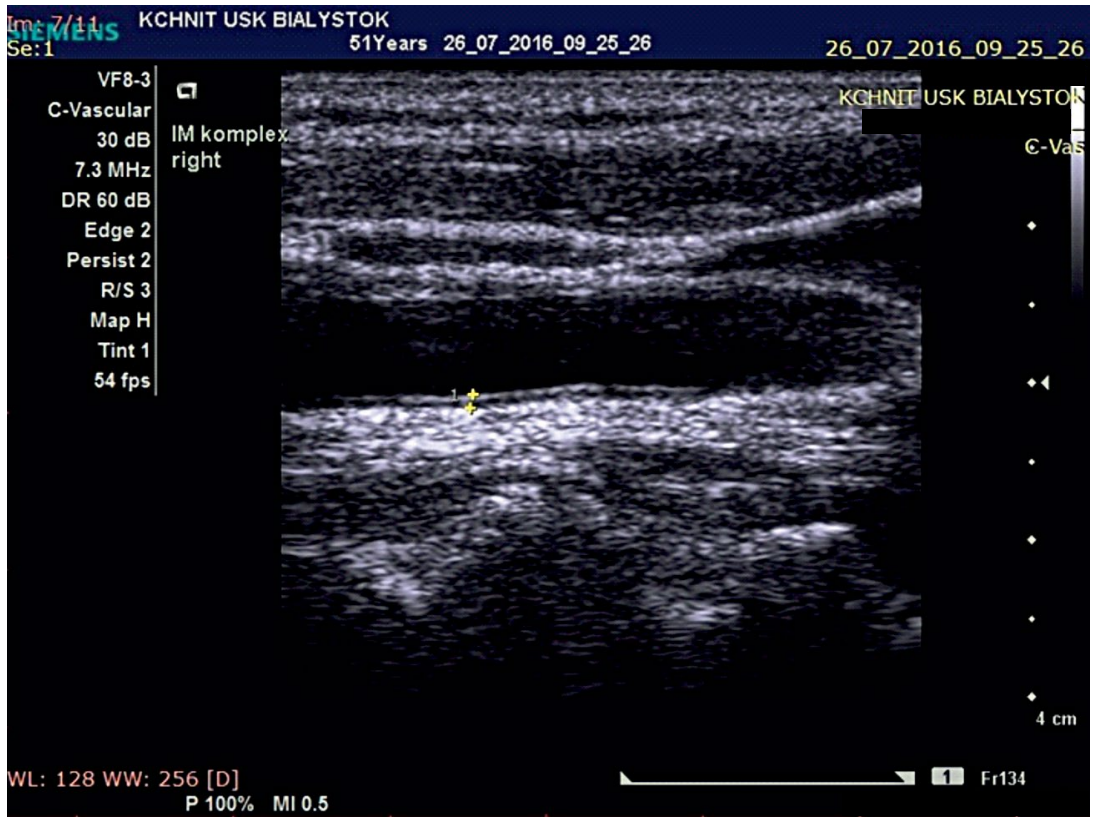

Figure I. Intima-media thickening (ultrasound picture: A. Płoński)

Two biomechanical forces acting on the surface of arterial walls tensile stress and shear stress. The latter is important in the view of atherosclerotic pathomechanism. Atherosclerotic plaque forms in very specific places, i.e. internal curvature of vessels, bifurcations and origin sites of lateral branches, where oscillatory shear stress act. The above shear stress leads to endothelial damage [13].

A layer of endothelial cells forms a highly specialized surface that has direct contact with blood. By continual exposure to cells and substances contained in blood, the endothelium secretes a number of molecules and factors regulating functions of the vascular walls depending on the prevailing conditions [14]. Significant lesions in endothelial cells precede atherogenesis [14]. Endothelial cells, which are subject to changes in haemodynamic and physicochemical conditions, undergo functional disorders mainly with regard to the secretion of endothelial nitric oxide synthase (eNOS) that is responsible for NO production in endothelial cells from L-arginine[ [4].

$\mathrm{NO}$ is a gas non-persistent molecule, however, it quickly penetrates into the vascular wall, where it influences the arterial smooth muscle cells while ensuring proper arterial wall tone [15]. In addition, NO inhibits leucocyte and blood platelet adhesion to the endothelium, stimulates reconstructive processes within the endothelium, and inhibits smooth muscle cell migration from the tunica media to the tunica intima [I5].

Healthy endothelium preserves the balance in terms of contractile function and counteracting potential inflammation of the arterial wall [16]. A decreased $\mathrm{NO}$ level leads to many pro-atherogenic phenomena, such as intensified vasoconstriction, increased blood platelet aggregation in the endothelium, oxidative modification of lipoproteins accumulated in the tunica intima, pro-proliferative [17] and pro-migratory effects towards vascular smooth muscle cells (VSMCs) [18], as well as adhesion and infiltration of the endothelium by monocytes and lymphocytes, which then, migrate to the subendothelial space and initiate local inflammation [19].

Factors that damage the endothelium and initiate chronic inflammation lead to the gradual degradation of the arterial wall. A process of atherosclerotic lesion formation starts with a pathologic intimal thickening $[20,21]$. The first phenomenon that appears in the process of the atherosclerotic lesion formation is adaptive thickening of the intima that is caused by VSMCs accumulated in proteoglycan-rich matrix [20], what in turn leads to thickening of the intima media complex. These sites are predisposed to atherosclerotic plaque formation [2I] (Fig. I).

\section{Plaque development}

lipid metabolism disorders influence the change in the function and structure of endothelial cells. In case of hypercholesterolaemia, endothelial cells (ECs) change their structure [14]. Endothelial cells subject to contact with blood rich in cholesterol and triglycerides change their phenotype into a secretory phenotype [14]. 
Connections between cells become more permeable [14]. Shear stress forces acting on vascular walls facilitate permeation of low-density lipoproteins (LDL) through the tunica intima by increased pressure and causes repetitive microtrauma in the arterial endothelium [14]. Low-density lipoproteins (LDL), which transport cholesterol to tissues, may bond with arterial proteoglycans by means of apolipoprotein B (a protein component of LDL) [22]. Minimally modified LDL (mmLDL) permeate the subintimal space. Lipoproteins that accumulate under the endothelial layer undergo numerous modifications and are oxidized to oxLDL [23]. Moreover, lipoproteins may permeate the subintimal space via transcytosis. Endothelial cells, inside which lipoproteins are confined, cumulate lipids and become endothelial-derived foam cells [24].

Adhesion molecules [ICAM (intercellular adhesion molecule) VCAM (vascular cell adhesion molecule)] that appear on the endothelial surface allow for monocyte infiltration of the subintimal space; the monocytes aim at eliminating oxidized lipoproteins [25]. Monocytes transform into macrophages, which bind large numbers of oxLDL by SR receptors (scavenger receptors) while absorbing them and becoming foam cells [25]. The above changes form fatty streaks in vascular walls [26] that in fact are accumulated foam cells within the tunica intima. Foam cells (derived mainly from macrophages, but also from VSMCs, and ECs) [24], with autophagy defect, are characterized by accumulation of damaged organelles, what leads to cell death [27] with subsequent release of its content, including accumulated lipids.

When macrophages undergo apoptosis, their cholesterol-rich content gets out into the extracellular space [27]. Chemotactic signals attract other macrophages what leads to a vicious circle and gradual formation of a necrotic core [27] between the internal and external elastic lamina, which contains mainly lipids and disintegrated dead cells.

Lipids accumulate in cells and extracellularly. Vascular smooth muscle cells (VSMCs) are attracted to these sites [28]; they migrate from tunica media to tunica intima drawn by a chemotactic signal of T-lymphocytes that secrete interferon gamma (IFN gamma) [28]. VSMCs that moved into the tunica intima change their phenotype in order to repair damaged vascular wall - from a cell that is able to contract into a cell that has an ability to proliferate and secrete extracellular matrix. Having changed the phenotype, VSMCs produce extracellular matrix to stabilize the formed change and limit the inflammation within it [28]. Extracellular matrix consists of connective tissue parts, such as collagen and proteoglycans that are deposited within the plaques, predominantly close to its surface, where the fibrous cap is formed. Strength of the protective fibrous cap depends on its structure conditioned by type I and type 3 collagen [28]. At an advanced stage of atherosclerotic plaque development, VSMCs play an important protective function. Their presence is of key importance in the process of fibrous cap formation and maintaining its proper thickness [29]. A fibrous cap maintains the plaque integrity and separates lipid-rich and thrombogenic content of the core from the arterial lumen [28].

Atherosclerotic plaque growth and development takes place over many years. A microscopic cross-section of the plaque shows its history, in which the following foci may be observed: neovascularization, intraplaque haemorrhage [IPH] and thrombus formation. Development of atherosclerosis leads not only to arterial stenosis but also it remodels the arterial wall [30]. Such remodelling may have a significant influence on the clinical presentation of the disease. In some cases the plaque may not grow concentrically narrowing the vascular lumen, but spread eccentrically. It results from an increased blood flow velocity through the artery due to stenosis progression and acting shear stress [30]. In such conditions, the endothelium secretes considerable amounts of nitric oxide. NO causes a compensatory dilation of the lumen that becomes permanently remodelled over time [30]. Such a type of atherosclerotic plaque may not cause a hemodynamically significant arterial stenosis for many years. This phenomenon is called a positive remodelling of a vascular wall [30]. Negative remodelling is a decrease in a vascular diameter due to arterial wall fibrosis being a result of a long-lasting atherosclerotic process which leads to a faster stenosis progression and plays an important role in a restenosis mechanism after percutaneous transluminal angioplasty (PTA) procedures [30].

\section{Atherosclerotic plaque instability}

Stability of atherosclerotic plaque is ensured by a thick fibrous cap with high collagen content, a considerable amount of extracellular matrix, small necrotic core and calcifications (Fig. 2). Moreover, plaque stability depends on the level of its infiltration through inflammatory cells [3I].

Unstable plaque may be described as plaque that through a sequence of events may lead to ischaemia of tissues supplied by an atherosclerotic artery. It is a plaque that may lead to ischaemic episodes and clinical consequences. Unstable plaque in the carotid artery can be defined as a plaque in which specific features of morphological structure predisposing it to embolization with thrombogenic material are confirmed. Unstable plaque is characterized by a large lipid core that is a result of lipid accumulation in cells and extracellularly, as well as a thin fibrous cap deficient in collagen fibres [3I] 


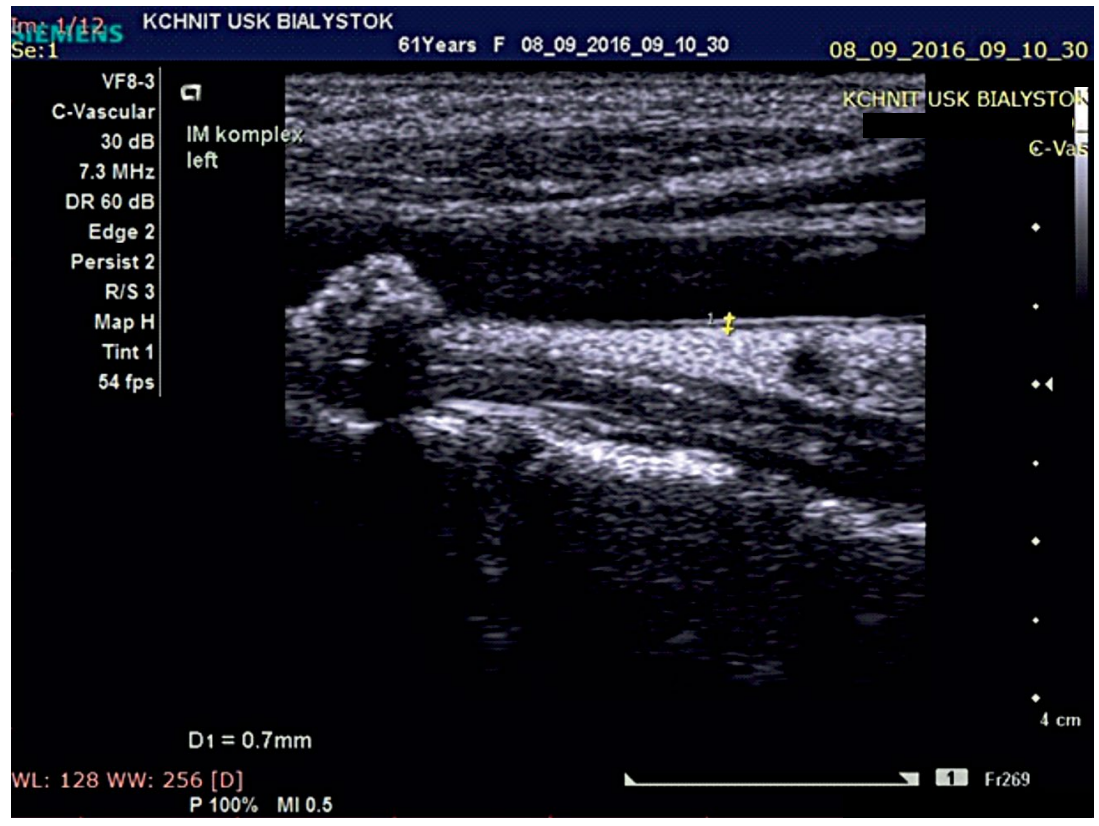

Figure 2. Stable calcified carotid atherosclerotic plaque (ultrasound picture: A. Płoński)

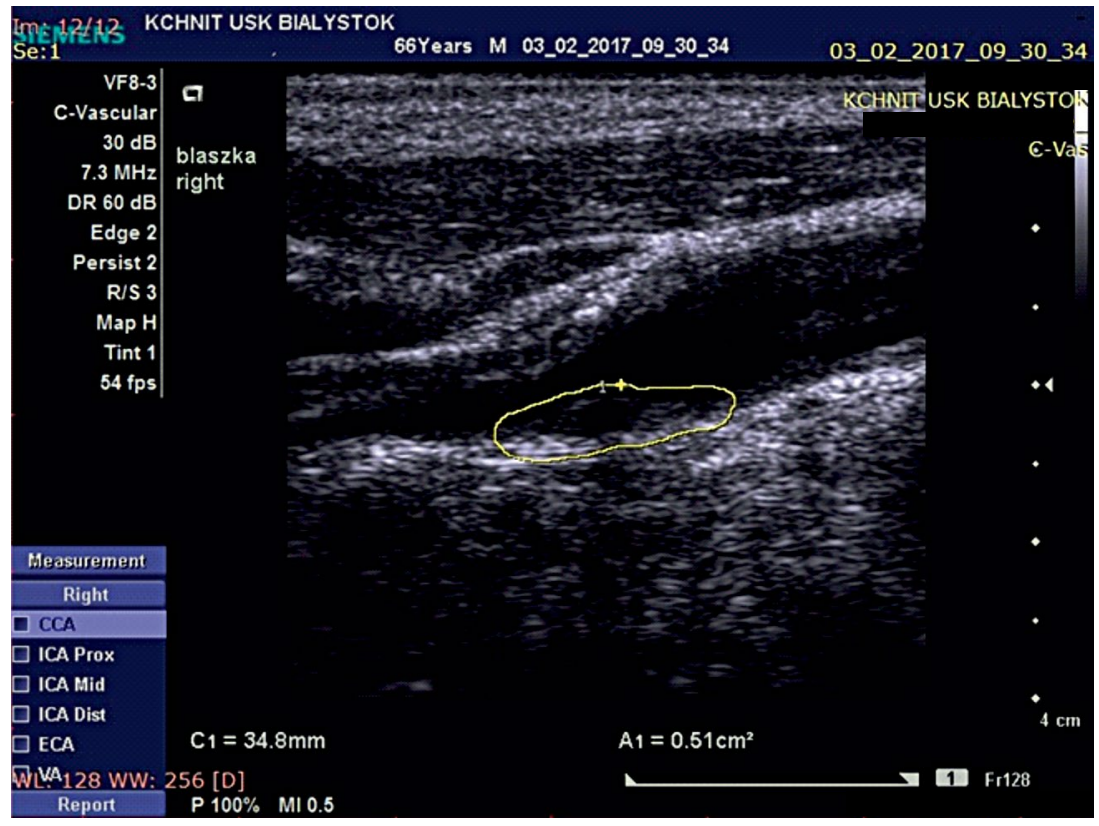

Figure 3. Unstable „soft” carotid atherosclerotic plaque (ultrasound picture: A. Płoński)

(Fig. 3). American Heart Association (AHA) classifies unstable plaque as type 5 and 6 [32] (Table I).

As a result of enlarging necrotic core, the cap undergoes gradual thinning associated with its stretching. The cap may be also thinned as a result of increased degradation of collagen fibres within it. This is caused by the activity of matrix metalloproteinases (MMPs) released by macrophages activated by chemotactic factors [28]. Furthermore, the structure of fibrous cap may be weakened when collagen production decreases due to apoptosis of a large number of VSMCs [28]. Some authors claim that aggrecan deposits (mainly proteoglycan) may induce VSMCs apoptosis [33].

In balanced conditions, healthy endothelium secretes large amounts of $\mathrm{NO}$ that stimulates aggrecanase function - an enzyme that decomposes aggrecan de- 
Table I. AHA classification of atherosclerotic plaque (conventional and modified classification for MRI) [32]

\begin{tabular}{|c|c|}
\hline Conventional AHA Classification & Modified AHA Classification for MRI \\
\hline Type I: Initial lesion with foam cells & \multirow[t]{2}{*}{ Type I-II: near — normal wall thickness, no calcification } \\
\hline Type II: Fatty streak with multiple foam cell layers & \\
\hline Type III: Preatheroma with extracellular lipid pools & $\begin{array}{l}\text { Type III: diffuse intimal thickening or small eccentric plaque } \\
\text { with no calcification }\end{array}$ \\
\hline Type IV: Atheroma with a confluent extracellular lipid core & \multirow{2}{*}{$\begin{array}{l}\text { Type IV-V: plaque with a lipid or necrotic core surrounded } \\
\text { by fibrous tissue with possible calcification }\end{array}$} \\
\hline Type V: Fibroatheroma & \\
\hline $\begin{array}{l}\text { Type VI: Complex plaque with possible surface defect, } \\
\text { hemorrhage, or thrombus }\end{array}$ & $\begin{array}{l}\text { Type VI: complex plaque with possible surface defect, } \\
\text { hemorrhage, or thrombus }\end{array}$ \\
\hline Type VII: Calcified plaque & Type VII: Calcified plaque \\
\hline Type VIII: Fibrotic plaque without a lipid core & $\begin{array}{l}\text { Type VIII: Fibrotic plaque without lipid core } \\
\text { and with a possible small calcification }\end{array}$ \\
\hline
\end{tabular}

posits [33]. When the endothelium is damaged, mRNA coding large amounts of proteoglycans, especially aggrecan, undergoes overexpression. Subendothelial aggrecan leads to increased uptake of large numbers of lipoproteins, and to an increased VSMCs apoptosis [33]. VSMCs that undergo apoptosis in large numbers lead to a decrease in production of collagen and other components of extracellular matrix, exacerbation of existing inflammation, and further enlargement of plaque necrotic core, in which residues of disintegrated cells cumulate [28].

Unstable plaque is characterized by a higher level of VSMCs apoptosis than stable plaque. Moreover, over time VSMCs apoptosis leads to calcifications within the plaque [34]. The above phenomena weaken the structure of the fibrous cap, especially within the weakest point of its structure called a cap shoulder. The cap shoulder, where VSMCs are in minority and macrophages in the majority, is the place where plaque rupture occurs most frequently [35]. Thinning of the fibrous cap in carotid atherosclerotic plaque is an independent risk factor for ischaemic episodes [36]. A large necrotic core contains a large number of accumulated lipids and free cholesterol, which undergoes crystallization and causes an increase in plaque volume as well as stretching of the fibrous cap, what may lead to it being damaged [37]. In addition, fissures in the cap are associated with parallel arrangement of cholesterol crystals in the core [37] what reflects high blood pressure in the artery. Sometimes also asymptomatic silent plaque ruptures occur. VSMCs repair the damage and reorganize the blood clot that appeared [38]. In histopathological examinations, advanced atherosclerotic plaque shows numerous rupture and repair sites, which leads to a gradual accretion of the plaque to the inside of the vessel and progressing stenosis [38]. A damage repair process requires active VSMCs proliferation and intense matrix production, which may be insufficient considering the advanced VSMCs apoptosis [39].

Inflammatory cells play a crucial role in both plaque formation and complications resulting from atherosclerotic plaque development. Inflammatory cells such as macrophages and T-lymphocytes are present in plaque at every stage of its development and exhibit features that destabilize the plaque, what is associated with an uncontrollable secretion of large quantities of IFN gamma by T-lymphocytes (CD4+ CD28-) [40]. Additionally, these cells damage endothelial cells in a direct way. It has been shown that activated macrophages and myocytes present in plaque show MHC II (Major Histocompatibility Complex II) expression [4I]. They have an ability to present antigen to the T-lymphocytes [4I]. Lymphocyte activation involves secretion of pro-inflammatory cytokines and intensification of the inflammatory response in the vascular wall. Pro-inflammatory cytokines, released in the atherosclerotic plaque, exert both local and systemic effects [42]. They stimulate the liver to synthetize proteins being inflammatory state markers (CRP, fibrinogen) [42]. IFN gamma secreted by T-lymphocytes stimulates macrophages to secrete MMPs. MMPs significantly destabilize the plaque in subsequent stages of its development $[43,44]$.

ICAM-I (intercellular adhesion molecule) and LFA-I (lymphocyte function associated molecule) are key molecules participating in adhesion and migration of inflammatory cells [45]. Expression of these molecules correlates positively with the level of plaque macrophage infiltration and the level of T-lymphocyte migration to the tunica intima [45]. Plaque destabilization takes place due to the intensification of a chronic inflammatory process within the plaque and substantial infiltration by the mentioned inflammatory cells with all consequences of the process [45]. 


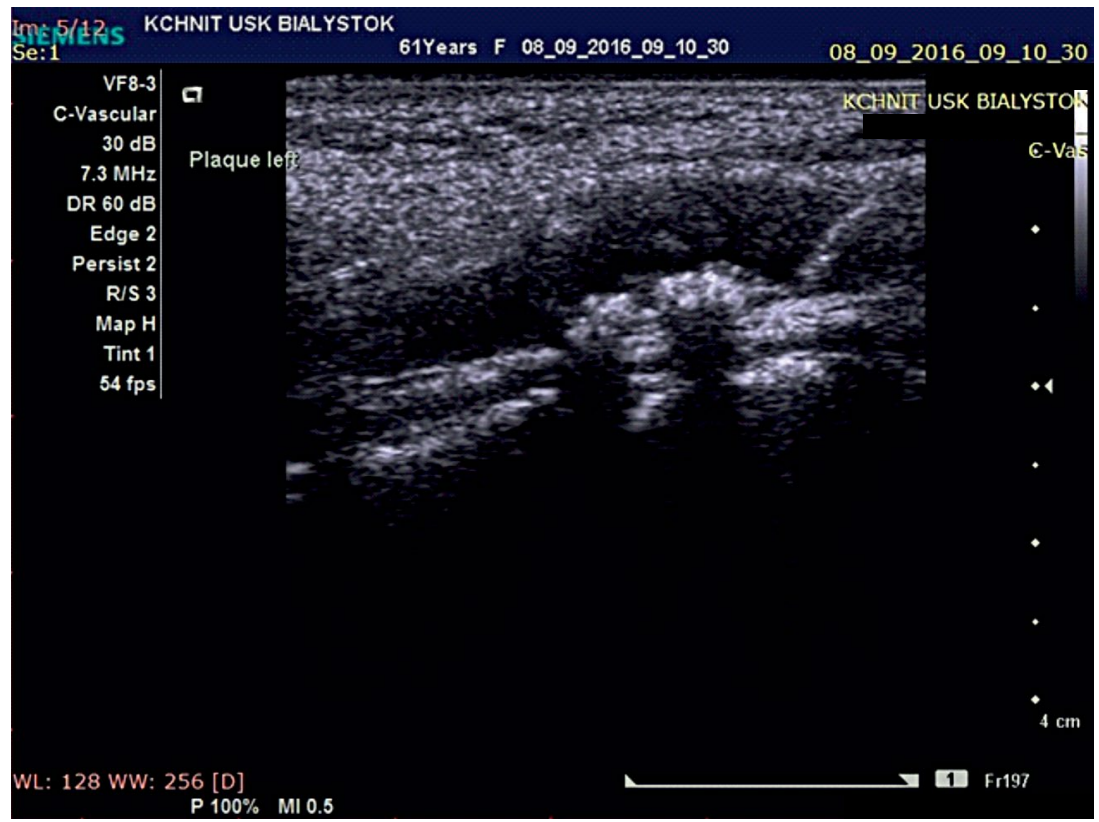

Figure 4. Unstable carotid plaque with ulceration (ultrasound picture: A. Płoński)

Unstable plaque is often confirmed to have intraplaque haemorrhage originating from pathological spread of vasa vasorum [46], or ulcerations [47] (Fig. 4). Fragile vasa vasorum, which develop as a result of hypoxia, are the main source of intraplaque haemorrhages [46]. An intraplaque haemorrhage (IPH) predicts an episode of cerebral ischaemia [47]. Furthermore, it is a factor predisposing for a recurrent cerebral ischaemic episode [48]. Upon MRI imaging [49] IPH is more often revealed in symptomatic patients $[47,50]$. Abnormal vessels formed during neovascularization may rupture spontaneously or may lead to chronic intraplaque haemorrhage. Intraplaque haemorrhages, together with cell apoptosis, play an important role in necrotic core development [49]. Haemoglobin released from erythrocytes destabilizes plaque [49] due to induction of inflammatory state. Iron released from haemoglobin forms deposits, while causing a formation of large amounts of reactive oxygen species (ROS) [5 I], what in turn leads to oxidative stress, and significantly destabilizes the plaque. An intraplaque haemorrhage classifies plaque as type $6 \mathrm{~b}$ according to AHA classification [52] (Table I).

Haptoglobin $(\mathrm{Hp})$ is a key protein that binds free haemoglobin and protects from the consequences of its release. In addition, haptoglobin promotes biding the haemoglobin by scavenger receptors on the surface of macrophages [53]. It is believed that genetic polymorphism (two alleles) of $\mathrm{Hp}$ influences its anti-inflammatory and anti-oxidative response to intraplaque haemorrhages. In the case of $\mathrm{Hp} 2-2$ genotype, a greater risk for cardiovascular diseases, including atherosclerosis, is observed [53].

An increased amount of aging cells is detected in atherosclerotic plaque, what is confirmed in studies on specific markers such as $\mathrm{SaG}$ (senescence-associated galactosidase), whose significant increase is noticed within atherosclerotic plaque as compared with a healthy vascular wall [54]. Cell aging within a lesion may be divided into 2 types: replicative and inductive. The first one is characterized by telomere shortening at the edges of chromosomes. The second type is induced by external factors, e.g. oxidative stress or ionizing radiation, and leads to premature cell aging [54]. Repair of plaque damages requires VSMCs replication, however, the more advanced the process of atherosclerotic plaque development, the higher the level of VSMCs aging [54].

Within the cap shoulder, there is a larger number of aging cells exhibiting telomere shortening [55] and a decreased level of sheltering proteins, such as TRF-2 (telomeric repeat-binding factor-2), what leads to increased DNA damages as compared with cells from a healthy arterial wall [56]. Aging VSMCs have limited replication abilities and an increased number of immune receptors, and thus, generate a highly pro-inflammatory environment [57]. Regulating the balance between cell death and aging, as well as proliferation and migration are of key importance in atherogenesis and maintaining plaque stability.

Many scientists confirmed cell apoptosis within plaque [58]. As the plaque develops, the cell apop- 


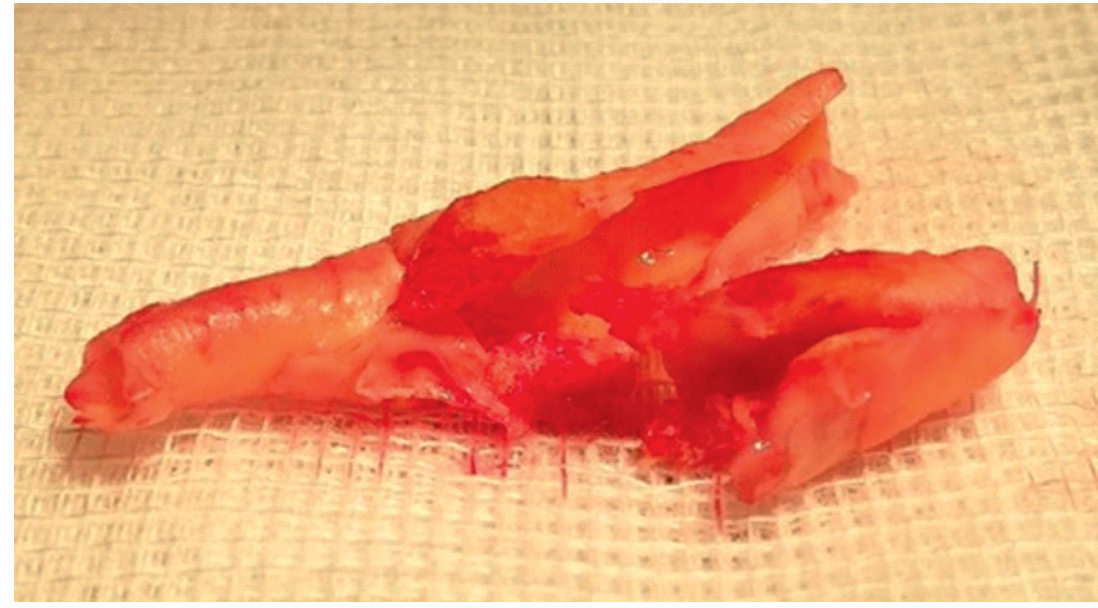

Figure 5. Carotid atherosclerotic plaque: postoperative material (photo: N. Wiśniewska)

tosis increases. In advanced atherosclerotic plaque, extracellular matrix separates cells from each other and limits their migration and phenotype changes. Macrophage-infiltration of the plaque leads to matrix degradation, promotion of VSMCs phenotype changes, and migration of both cell types [59]. Changes in cell phenotype often led to their incorrect identification: both in cases of VSMCs that changed their phenotype to macrophage-like cells, and macrophages that changed their phenotype to VSMCs-like cells $[59,60]$.

VSMCs, which so far played a stabilizing and protective role in the advanced stage of plaque development, may change their phenotype to macrophage-like cells that induce inflammatory state $[59,60]$. In VSMCs, genes responsible for facilitating phagocytosis undergo expression, however, their expression in macrophage-like cells is weaker than in macrophages, and consequently, it is conducive to further accumulation of cell residue [59-6I].

Within an advanced atherosclerotic lesion, a reverse phenotype change may also occur - macrophages change into VSMCs-like cells. Despite numerous reports on the importance of VSMCs in the stabilization of atherosclerotic plaque [6I], studies showed that VSMCs- like cells and being in reality bone marrow-derived cells have the potential to destabilize the plaque as opposed to VSMCs derived from arterial walls [62].

\section{Risk evaluation}

current guidelines- Management of Atherosclerotic Carotid and Vertebral Artery Disease: 2017 Clinical Practice Guidelines of the European Society for Vascular Surgery (ESVS 2017) [1] indicate groups of patients that may achieve the greatest benefits from surgical treatment, and determine groups of patients that should be treated only by best medical treatment (BMT) pharmacotherapy. The greatest benefits from surgical treatment are achieved by symptomatic patients with 70-99\% carotid artery stenosis (according to NASCET) estimated on the basis of CT or MRI scans, or Duplex Doppler exam performed twice by independent ultrasonographers. Symptomatic patients are defined as individuals who had a documented stroke within the past 6 months or transient ischaemic attack (TIA). Such patients are recommended to undergo classic carotid endarterectomy (CEA) (Fig. 5) in combination with best pharmacotherapy (BMT), i.e. ASA in the dose of $75 \mathrm{mg}$ and statin (recommendation class la). In some cases, the surgeon may consider carotid artery stenting (CAS) in combination with BMT instead of CEA.

In symptomatic patients with lower stenosis, degree of $50-69 \%$, surgical treatment should be considered individually since this group will not achieve equal benefits from the treatment as the patients with stenosis above $70 \%$. In such cases, endarterectomy (Ila) is a preferred method. In some cases, CAS (Ilb) should be considered.

Patients with an occluded or almost occluded internal carotid artery should not undergo surgical treatment regardless of the history regarding past ischaemic episodes. This group of patients should undergo treatment with the use of BMT pharmacotherapy (la). However, current guidelines show that there is a group of patients that is described as patients with high risk for stroke despite the negative history of past ischaemic episodes during the past 6 months. It is a group of asymptomatic patients with a confirmed $60-99 \%$ internal carotid artery stenosis in imaging examinations who have one or more additional factors suggesting a higher stroke risk. In these patients, the use of pharmacotherapy only may not be sufficient and it is recommended to 
consider surgical treatment [63]. A preferred method is carotid endarterectomy (CEA) in combination with BMT (Ila) pharmacotherapy. In high-risk cases of CEA performance, carotid artery stenting (CAS) (Ilb) may be considered.

The Carotid Revascularization Endarterectomy versus Stenting Trial (CREST) concluded that there was no significant difference in the rates of the primary end point between CAS and CEA procedures [64]. However, the International Carotid Stenting Study (ICSS) showed that CAS was less safe than CEA in symptomatic patients [65].

Present ESVS Guidelines recommend CEA rather than CAS as a preferable operative method, but CAS may be considered as an alternative to CEA in some patients [I].

Factors that indicate a higher stroke risk include specific clinical conditions or morphological features of atherosclerotic plaques in asymptomatic patients that were so far treated pharmacologically. Stratification of surgical risk should include a combination of plaque morphological features and the degree of arterial stenosis as well as specific clinical data. In recent years many studies identified such factors and suggested prophylactic surgical interventions before an ischaemic episode occurs [63].

Current ESVS guidelines list plaque hypoechogenicity as a plaque morphological feature that shows its instability. Hypoechogenic plaque is associated with significantly higher stroke risk (Fig. 3). It was showed that plaque hypoechogenicity is associated with a lipid-rich necrotic core and/or intraplaque haemorrhage (IPH) [66, 67]. Both lipid-rich "soft" necrotic core and intraplaque haemorrhage are factors with a documented potential to destabilize an atherosclerotic plaque. Furthermore, patients with plaque involving a large area of the artery are subject to a higher risk of ischaemic episodes. Large plaque with an estimated area above $80 \mathrm{~mm}^{2}$ is associated with a significantly higher stroke risk [68], what is often associated with the presence of a large necrotic core.

Another parameter visible during imaging examinations is juxtaluminal black area (JBA). In ultrasound, JBA is visible as a hypoechogenic area of pixels without a visible cap with a greyscale value $<25$ adjacent to the arterial lumen [69]. The area indicated a considerable thinning or loss of cap continuity at its shoulder. It is an area whose size is directly associated with a risk for the stoke. JBA $>8 \mathrm{~mm}^{2}$ is suggested to be a cutoff point [69]. This parameter may be used to isolate a group of asymptomatic patients with a high risk for stroke; also, JBA ultrasound evaluation may help to avoid unnecessary surgery in asymptomatic patients [70]. The Asymptomatic Carotid Stenosis and Risk of Stroke (ACSRS) study confirmed a connection between JBA and its size with high stroke risk. Weak points or deficits in the structure of the fibrous cap, especially in the cap shoulder region, are associated with a high embolization potential of the plaque [69].

Intraplaque haemorrhage (IPH) can be evaluated using a simple MRI examination. IPH is considered as a plaque instability factor and is a feature predisposing for ischaemic stroke. A meta-analysis [7I] showed a strong predictive value of IPH and the presence of a large lipid core as well as a thin/ruptured fibrous cap confirmed upon the MRI exam.

Another group of patients with a high stroke risk are patients with internal carotid artery stenosis in whom subsequent examinations confirmed plaque growth and stenosis progression ACSRS (The Asymptomatic Carotid Stenosis and Risk of Stroke) [72, 73]. In the published studies the stroke risk increased with plaque progression and also increased proportionally more depending on the initial stenosis degree. Patients with a higher stenosis degree and its progression were burdened with a higher risk than patients with a smaller stenosis degree and its progression. Apart from morphological features of the plaque, the following clinical data and results of additional examination should be taken into account while qualifying asymptomatic patients with 60-99\% internal carotid artery stenosis to a surgical procedure: contralateral TIA/stroke, spontaneous microembolization confirmed upon transcranial doppler (TCD), silent stroke confirmed upon imaging examination, and reduced cerebrovascular reserve $(\mathrm{CVR})[\mathrm{I}]$.

\section{Conclusion}

stroke risk assessment is related to the evaluation of atherosclerotic plaque in the internal carotid artery in terms of its potential for embolization. Plaque with a high potential for embolization is described as unstable plaque. Morphological structure of unstable atherosclerotic plaque is reflected in features indicated by ESVS and described as high-risk factors for stroke that may be confirmed in patients who have been asymptomatic so far. Learning about morphological features of atherosclerotic plaque structure that carries the risk for embolization has significant clinical implications in the process of qualifying patients for surgical treatment. It is estimated that from a group of asymptomatic patients, about 10-15\% of individuals may achieve real benefits from a vascular intervention [63]. The results of the ongoing Asymptomatic Carotid Surgery Trial-2 (ACST-2) are awaited to estimate the role of the surgical methods in the treatment of asymptomatic patients [74]. We need more prospective clinical studies conducted on a large group of patients, and evaluating the significance of particular factors, including morphological structure 
of the plaque, as well as assessing which surgical methods in combination with the best pharmacotherapy would be the best for this group of patients.

\section{Conflict of interest}

None.

\section{References:}

I. Beręsewicz A. Skierczyńska A. Miażdżyca - choroba całego życia i całej populacji krajów cywilizacji zachodniej. Choroby Serca i Naczyń. 2006; 3(I): I-6.

2. Thompson RC, Allam AH, Lombardi GP, et al. Atherosclerosis across 4000 years of human history: the Horus study of four ancient populations. Lancet. 2013; 38I(9873): I21 I-1222, doi: 10.10I6/S0140-6736(I3)60598-X, indexed in Pubmed: 23489753.

3. Tendera M, Aboyans V, Bartelink ML, et al. ESC Guidelines on the diagnosis and treatment of peripheral artery diseases: Document covering atherosclerotic disease of extracranial carotid and vertebral, mesenteric, renal, upper and lower extremity arteries * The Task Force on the Diagnosis and Treatment of Peripheral Artery Diseases of the European Society of Cardiology (ESC). European Heart Journal. 20II; 32(22): 285I-2906, doi: I0.1093/eurheartj/ehr2II.

4. Paraskevas KI, Veith FJ, Spence JD. How to identify which patients with asymptomatic carotid stenosis could benefit from endarterectomy or stenting. Stroke and Vascular Neurology. 2018; 3 (2): 92-100.

5. Naylor AR, Ricco JB, de Borst GJ, et al. Editor's Choice - Management of Atherosclerotic Carotid and Vertebral Artery Disease: 2017 Clinical Practice Guidelines of the European Society for Vascular Surgery (ESVS). Eur J Vasc Endovasc Surg. 2018; 55(I): 3-81, doi: 10.1016/j.ejvs.2017.06.021, indexed in Pubmed: 28851594.

6. Heo KS, Fujiwara K, Abe Ji. Shear stress and atherosclerosis. Mol Cells. 20I4; 37(6): 435-440, doi: 10.14348/molcells.2014.0078, indexed in Pubmed: 2478I 409.

7. Jóźwicka M. Głąbiński A. Patogeneza rozwoju blaszki miażdżycowej w tętnicach szyjnych. Choroby naczyniowe. Aktualności Neurologiczne. 20I I; I I(4): 265-273.

8. Rognoni A, Cavallino C, Veia A, et al. Pathophysiology of Atherosclerotic Plaque Development. Cardiovascular \& Hematological Agents in Medicinal Chemistry. 2015; 13(1): 10-13, doi: 10.217 4/187/5257/3666/4I218163425.

9. Wang J, Wei Bo, Cao S, et al. Identification by microarray technology of key genes involved in the progression of carotid atherosclerotic plaque. Genes Genet Syst. 2014; 89(6): 253-258, doi: 10.1266/ggs.89.253, indexed in Pubmed: 25948। 19.

10. Liu W, Zhao Y, Wu J. Gene expression profile analysis of the progression of carotid atherosclerotic plaques. Mol Med Rep. 2018; 17(4): 5789-5795, doi: 10.3892/mmr.2018.8575, indexed in Pubmed: 29436628.

11. Libby P. Inflammation in atherosclerosis. Nature. 2002; 420(6917): 868-874, doi: 10.1038/nature01323, indexed in Pubmed: 12490960 .

12. Landmesser U, Hornig B, Drexler H. Endothelial function: a critical determinant in atherosclerosis? Circulation. 2004; 109(21
Suppl I): ||27-II33, doi: |0.I |6|/0I.CIR.0000|2950|.88485. If, indexed in Pubmed: 15173060.

13. Wasilewski J, Kiljański T, Mirota $K$, et al. Znaczenie naprężeń ścinających i rola numerycznej mechaniki płynów w badaniach nad patomechanizmem miażdżycy. Folia Cardiologica Excerpta. 2012 ; 7(2): 95-100.

14. Gerrity R. Arterial endothelial structure and permeability as It relates to susceptibility to atherogenesis. Pathobiology of the Human Atherosclerotic Plaque. 1990: 13-45, doi: 10.1007/978I-46|2-3326-8_2.

15. Mordarski S. The role of nitric oxide in neurotransmission. Medycyna Rodzinna. 2004(I): 13-15.

16. Tomczyk M. Nowak W. Jaźwa A. Śródbłonek w fizjologii i patogenezie chorób. Postępy biochemii. 2013; 59(4): 357-364.

17. Jeremy JY, Rowe D, Emsley AM, et al. Nitric oxide and the proliferation of vascular smooth muscle cells. Cardiovasc Res. 1999; 43(3): 580-594, doi: 10.1016/s0008-6363(99)00I7I-6, indexed in Pubmed: 10690330.

18. Sarkar R, Meinberg EG, Stanley JC, et al. Nitric oxide reversibly inhibits the migration of cultured vascular smooth muscle cells. Circ Res. 1996; 78(2): 225-230, doi: 10.1161/01.res.78.2.225, indexed in Pubmed: 8575065.

19. Davignon J, Ganz P. Role of endothelial dysfunction in atherosclerosis. Circulation. 2004; 109(23 Suppl I): III27-III32, doi: I0. I 16I/0I. CIR.0000I3I5I5.03336.f8, indexed in Pubmed: 15198963.

20. Johnson JL. Emerging regulators of vascular smooth muscle cell function in the development and progression of atherosclerosis. Cardiovasc Res. 2014; 103(4): 452-460, doi: 10.1093/cvr/ cvul7I, indexed in Pubmed: 25053639.

21. Kolodgie FD, Burke AP, Nakazawa G, et al. Is pathologic intimal thickening the key to understanding early plaque progression in human atherosclerotic disease? Arterioscler Thromb Vasc Biol. 2007; 27(5): 986-989, doi: 10.1161/ATVBAHA.0000258865.44774.4I, indexed in Pubmed: 17442894.

22. Olofsson SO, Borèn J. Apolipoprotein B: a clinically important apolipoprotein which assembles atherogenic lipoproteins and promotes the development of atherosclerosis. J Intern Med. 2005; 258(5): 395-4I0, doi: I0.1 I I I/j. I365-2796.2005.01556.x, indexed in Pubmed: 16238675.

23. Parthasarathy S, Raghavamenon A, Garelnabi MO, et al. Oxidized low-density lipoprotein. Methods Mol Biol. 2010; 610: 403-4I7, doi: 10.1007/978-1-60327-029-8 24, indexed in Pubmed: 20013192.

24. Chistiakov D, Melnichenko A, Myasoedova V, et al. Mechanisms of foam cell formation in atherosclerosis. Journal of Molecular Medicine. 2017; 95(II): II53-I I65, doi: 10.1007/s00 I09-017-1575-8.

25. Yu XH, Fu YC, Zhang DW, et al. Foam cells in atherosclerosis. Clin Chim Acta. 2013; 424: 245-252, doi: 10.1016/j. cca.2013.06.006, indexed in Pubmed: 23782937.

26. Stary $H C$, Chandler $A B$, Dinsmore RE, et al. A definition of advanced types of atherosclerotic lesions and a histological classification of atherosclerosis. A report from the Committee on Vascular Lesions of the Council on Arteriosclerosis, American Heart Association. Arterioscler Thromb Vasc Biol. 1995; 15(9): 1512-1531, doi: 10.1 161/01.atv. 15.9.15 |2, indexed in Pubmed: 7670967.

27. Seimon T, Tabas I. Mechanisms and consequences of macrophage apoptosis in atherosclerosis. Journal of Lipid Research. 2009; 50(April Supplement): 382-387. 
28. Rudijanto A, Rudijanto A, Rudijanto A, et al. IO HAT Investigator Group. The role of vascular smooth muscle cells on the pathogenesis of atherosclerosis. Acta Medica Indonesiana. 2007; 39(2): 86-93.

29. Bennett MR, Sinha S, Owens GK. Vascular Smooth Muscle Cells in Atherosclerosis. Circ Res. 2016; 118(4): 692-702, doi: 10.1 I6I/CIRCRESAHA.I I5.30636I, indexed in Pubmed: 26892967.

30. Glagov S, Ko C, Bassiouny HS. Principles of vascular remodelling. In: Lanzer P, Topol EJ. ed. Pan vascular medicine. Springer, Berlin-Heidelberg 2002: 232-24I.

31. Konishi T, Funayama N, Yamamoto T, et al. Pathological quantification of carotid artery plaque instability in patients undergoing carotid endarterectomy. Circ J. 2017; 82(I): 258-266, doi: 10.1253/circj.CJ-17-0204, indexed in Pubmed: 28757518.

32. Cai JM, Hatsukami TS, Ferguson MS, et al. Classification of human carotid atherosclerotic lesions with in vivo multicontrast magnetic resonance imaging. Circulation. 2002; 106(II): |368-1373, doi: 10.1 161/01.cir.0000028591.44554.f9, indexed in Pubmed: 12221054.

33. Kim SM, Huh JW, Kim EY, et al. Endothelial dysfunction induces atherosclerosis: increased aggrecan expression promotes apoptosis in vascular smooth muscle cells. BMB Rep. 2019; 52(2): 145-150, indexed in Pubmed: 30638179.

34. Clarke MCH, Littlewood TD, Figg N, et al. Chronic apoptosis of vascular smooth muscle cells accelerates atherosclerosis and promotes calcification and medial degeneration. Circ Res. 2008; 102(12): 1529-1538, doi: 10.1 161/CIRCRESAHA.108.175976, indexed in Pubmed: 18497329.

35. Libby P, Ridker PM, Hansson GK. Progress and challenges in translating the biology of atherosclerosis. Nature. 201 I; 473(7347): 317-325, doi: 10.1038/nature 10146, indexed in Pubmed: 21593864.

36. Hansson GK, Libby P, Tabas I. Inflammation and plaque vulnerability. J Intern Med. 2015; 278(5): 483-493, doi: 10.1 III/ /joim. 12406, indexed in Pubmed: 26260307.

37. Suhalim JL, Chung CY, Lilledahl MB, et al. Characterization of cholesterol crystals in atherosclerotic plaques using stimulated Raman scattering and second-harmonic generation microscopy. Biophys J. 2012; 102(8): 1988-1995, doi: 10.1016/j. bpj.2012.03.016, indexed in Pubmed: 22768956.

38. Mauriello A, Servadei F, Sangiorgi G, et al. Asymptomatic carotid plaque rupture with unexpected thrombosis over a non-canonical vulnerable lesion. Atherosclerosis. 201 I; 218(2): 356-362, doi: 10.1016/j.atherosclerosis.201 1.06.056, indexed in Pubmed: 21813127.

39. Bennett M. Apoptosis of vascular smooth muscle cells in vascular remodelling and atherosclerotic plaque rupture. Cardiovascular Research. 1999; 4I(2): 36I-368, doi: 10.1016/s00086363(98)002I 2-0.

40. Bullenkamp J, Dinkla S, Kaski JC, et al. Targeting T cells to treat atherosclerosis: odyssey from bench to bedside. Eur Heart J Cardiovasc Pharmacother. 2016; 2(3): 194-199, doi: 10.1093/ ehjcvp/pvw00I, indexed in Pubmed: 27418972.

4I. Hansson GK, Jonasson L, Holm J, et al. Class II MHC antigen expression in the atherosclerotic plaque: smooth muscle cells express HLA-DR, HLA-DQ and the invariant gamma chain. Clin Exp Immunol. 1986; 64(2): 26I-268, indexed in Pubmed: 3527502 .
42. Lind PM, Salihovic S, van Bavel B, et al. Circulating markers of inflammation and atherosclerosis. Atherosclerosis. 2003; 169(2): 203-214, doi: 10.1016/s0021-9150(03)00012-I, indexed in Pubmed: 12921971 .

43. Johnson JL, Dwivedi A, Somerville M, et al. Matrix metalloproteinase (MMP)-3 activates MMP-9 mediated vascular smooth muscle cell migration and neointima formation in mice. Arterioscler Thromb Vasc Biol. 201 I; 31(9): e35-e44, doi: 10.1161/ ATVBAHA.III.225623, indexed in Pubmed: 21719762.

44. Choi ET, Collins ET, Marine LA, et al. Matrix metalloproteinase- 9 modulation by resident arterial cells is responsible for injury-induced accelerated atherosclerotic plaque development in apolipoprotein E-deficient mice. Arterioscler Thromb Vasc Biol. 2005; 25(5): 1020-1025, doi: 10.1161/01. ATV.0000 |6 1275.82687.f6, indexed in Pubmed: 15746435.

45. Watanabe T, Fan J. Atherosclerosis and inflammation mononuclear cell recruitment and adhesion molecules with reference to the implication of ICAM- I/LFA-I pathway in atherogenesis. Int J Cardiol. 1998; 66 Suppl I: S45-53; discussion S55, doi: 10.1016/ /s0167-5273(98)00 I47-8, indexed in Pubmed: 995।802.

46. Parma L, Baganha F, Quax PHA, et al. Plaque angiogenesis and intraplaque hemorrhage in atherosclerosis. Eur J Pharmacol. 2017; 816: 107-115, doi: 10.1016/j.ejphar.2017.04.028, indexed in Pubmed: 28435093.

47. van Dijk AC, Truijman MTB, Hussain B, et al. Intraplaque Hemorrhage and the Plaque Surface in Carotid Atherosclerosis: The Plaque At RISK Study (PARISK). AJNR Am J Neuroradiol. 2015; 36(II): 2127-2133, doi: 10.3174/ajnr.A44I4, indexed in Pubmed: 26251429.

48. Altaf N, MacSweeney ST, Gladman J, et al. Carotid intraplaque hemorrhage predicts recurrent symptoms in patients with high-grade carotid stenosis. Stroke. 2007; 38(5): 1633-1635, doi: 10.1 16I/STROKEAHA.106.473066, indexed in Pubmed: 17379827.

49. McNally JS, Kim SE, Mendes J, et al. Magnetic Resonance Imaging Detection of Intraplaque Hemorrhage. Magn Reson Insights. 2017; 10: 1-8, doi: 10.1177/1178623X17694150, indexed in Pubmed: 2846944I.

50. Turc G, Oppenheim C, Naggara O, et al. HIRISC study investigators. Relationships between recent intraplaque hemorrhage and stroke risk factors in patients with carotid stenosis: the HIRISC study. Arterioscler Thromb Vasc Biol. 2012; 32(2): 492-499, doi: 10.1 161/ATVBAHA. III.239335, indexed in Pubmed: $2207525 \mathrm{I}$.

5I. Levy AP, Purushothaman KR, Levy NS, et al. Intraplaque hemorrhage. Curr Mol Med. 2006; 6(5): 479-488, indexed in Pubmed: 16918369.

52. Singh N, Moody AR, Gladstone DJ, et al. Moderate carotid artery stenosis: MR imaging-depicted intraplaque hemorrhage predicts risk of cerebrovascular ischemic events in asymptomatic men. Radiology. 2009; 252(2): 502-508, doi: 10.1 148/radiol.2522080792, indexed in Pubmed: 19508983.

53. Levy AP, Levy JE, Kalet-Litman S, et al. Haptoglobin genotype is a determinant of iron, lipid peroxidation, and macrophage accumulation in the atherosclerotic plaque. Arterioscler Thromb Vasc Biol. 2007; 27(1): 134-140, doi: 10.1161/01. ATV.000025 1020.24399.a2, indexed in Pubmed: 17068284.

54. Dimri GP, Lee X, Basile G, et al. A biomarker that identifies senescent human cells in culture and in aging skin in vivo. Proc 
Natl Acad Sci U S A. 1995; 92(20): 9363-9367, doi: 10.1073/ pnas.92.20.9363, indexed in Pubmed: 7568I33.

55. Karlseder J, Smogorzewska A, de Lange T. Senescence induced by altered telomere state, not telomere loss. Science. 2002; 295(5564): 2446-2449, doi: 10.1 I 26/science. 1069523 , indexed in Pubmed: I 1923537.

56. Richter T, Saretzki G, Nelson G, et al. TRF2 overexpression diminishes repair of telomeric single-strand breaks and accelerates telomere shortening in human fibroblasts. Mech Ageing Dev. 2007; 128(4): 340-345, doi: 10.1016/j.mad.2007.02.003, indexed in Pubmed: 17395247.

57. Song $Y$, Shen $H$, Schenten $D$, et al. Aging enhances the basal production of IL-6 and CCL2 in vascular smooth muscle cells. Arterioscler Thromb Vasc Biol. 2012; 32(I): 103-109, doi: 10.1161/ ATVBAHA. II I.236349, indexed in Pubmed: 220345 I0.

58. Geng Y, Libby P. Evidence for apoptosis in advanced human atheroma: colocalization with interleukin-lb converting enzyme. Am J Path. 1995; 147(25I): 266.

59. Alexander MR, Owens GK. Epigenetic control of smooth muscle cell differentiation and phenotypic switching in vascular development and disease. Annu Rev Physiol. 2012; 74: 13-40, doi: 10.1 146/annurev-physiol-0121 10-1423 15, indexed in Pubmed: 22017177

60. Owens GK, Kumar MS, Wamhoff BR. Molecular regulation of vascular smooth muscle cell differentiation in development and disease. Physiol Rev. 2004; 84(3): 767-80I, doi: 10.1 152/physrev.0004I.2003, indexed in Pubmed: 15269336.

61. Gomez D, Owens GK. Smooth muscle cell phenotypic switching in atherosclerosis. Cardiovasc Res. 2012; 95(2): 156-164, doi: 10.1093/cvr/cvs I I5, indexed in Pubmed: 22406749.

62. Yu H, Stoneman V, Clarke $M$, et al. Bone marrow-derived smooth muscle-like cells are infrequent in advanced primary atherosclerotic plaques but promote atherosclerosis. Arterioscler Thromb Vasc Biol. 2011; 31(6): 1291-1299, doi: 10.1161/ /ATVBAHA.I 1 0.218578, indexed in Pubmed: 21372299.

63. Paraskevas KI, Veith FJ, Spence JD. How to identify which patients with asymptomatic carotid stenosis could benefit from endarterectomy or stenting. Stroke and Vascular Neurology. 2018(3): 92-100.

64. Mantese VA, Timaran CH, Chiu D, et al. CREST Investigators. The Carotid Revascularization Endarterectomy versus Stenting Trial (CREST): stenting versus carotid endarterectomy for carotid disease. Stroke. 2010; 4I(10 Suppl): S3I-S34, doi: 10.1 I6I/ /STROKEAHA. I 1 0.595330, indexed in Pubmed: 20876500.

65. Ederle J, Dobson J, Featherstone RL, et al. International Carotid Stenting Study investigators. Carotid artery stenting compared with endarterectomy in patients with symptomatic carotid ste- nosis (International Carotid Stenting Study): an interim analysis of a randomised controlled trial. Lancet. 2010; 375(97/9): 985-997, doi: 10.1016/S0140-6736(10)60239-5, indexed in Pubmed: 20189239.

66. Grønholdt ML, Nordestgaard BG, Wiebe BM, et al. Echo-lucency of computerized ultrasound images of carotid atherosclerotic plaques are associated with increased levels of triglyceride-rich lipoproteins as well as increased plaque lipid content. Circulation. 1998; 97(1): 34-40, doi: 10.1161/01.cir.97.1.34, indexed in Pubmed: 9443429.

67. Polak JF, Shemanski L, O'Leary DH, et al. Hypoechoic plaque at US of the carotid artery: an independent risk factor for incident stroke in adults aged 65 years or older. Cardiovascular Health Study. Radiology. 1998; 208(3): 649-654, doi: 10.1 148/radiology.208.3.972284I, indexed in Pubmed: 972284I.

68. Nicolaides A, et al. Kakkos SK. Kyriacou E. Giffin M. Thomas DJ. Geroulakos G. Asymptomatic internal carotid artery stenosis and cerebrovascular risk stratification J Vasc Surg. 2010; 52: 1486.

69. Kakkos SK, Griffin MB, Nicolaides AN, et al. Asymptomatic Carotid Stenosis and Risk of Stroke (ACSRS) Study Group. The size of juxtaluminal hypoechoic area in ultrasound images of asymptomatic carotid plaques predicts the occurrence of stroke. J Vasc Surg. 2013; 57(3): 609-618.el; discussion 617, doi: 10.1016/j. jvs.2012.09.045, indexed in Pubmed: 23337294.

70. Griffin MB, Kyriacou E, Pattichis C, et al. Juxtaluminal hypoechoic area in ultrasonic images of carotid plaques and hemispheric symptoms. J Vasc Surg. 2010; 52(1): 69-76, doi: 10.1016/j. jvs.2010.02.265, indexed in Pubmed: 20537495.

71. Gupta A, Baradaran H, Schweitzer AD, et al. Carotid plaque $\mathrm{MRI}$ and stroke risk: a systematic review and meta-analysis. Stroke. 2013; 44(II): 307I-3077, doi: 10.1161/STROKEAHA. I I 3.00255I, indexed in Pubmed: 23988640.

72. Kakkos SK, Nicolaides AN, Charalambous I, et al. Asymptomatic Carotid Stenosis and Risk of Stroke (ACSRS) Study Group. Predictors and clinical significance of progression or regression of asymptomatic carotid stenosis. J Vasc Surg. 2014; 59(4): 956 967.el, doi: 10.1016/j.jvs.2013.10.073, indexed in Pubmed: 24377944

73. Wannarong T, Parraga G, Buchanan D, et al. Progression of carotid plaque volume predicts cardiovascular events. Stroke. 2013; 44: 1859-65.

74. Bulbulia R, Halliday A. The Asymptomatic Carotid Surgery Trial-2 (ACST-2): an ongoing randomised controlled trial comparing carotid endarterectomy with carotid artery stenting to prevent stroke. Health Technol Assess. 201 7; 2 I (57): I-40, doi: 10.3310/hta21570, indexed in Pubmed: 29019319. 